\title{
Les Quinze joies de mariage, édité par J. RYCHNEr, traduit par J.-C. MÜHLETHALER
}

\section{Maria Colombo Timelli}

\section{QpenEdition \\ Journals}

\section{Édition électronique}

URL : https://journals.openedition.org/studifrancesi/44759

DOI : 10.4000/studifrancesi.44759

ISSN : 2427-5856

\section{Éditeur}

Rosenberg \& Sellier

\section{Édition imprimée}

Date de publication : 1 août 2021

Pagination : 353

ISSN : 0039-2944

Référence électronique

Maria Colombo Timelli, «Les Quinze joies de mariage, édité par J. RYCHNEr, traduit par J.-C. MÜHLETHALER », Studi Francesi [En ligne], 194 (LXV | II) | 2021, mis en ligne le 06 septembre 2021, consulté le 15 octobre 2022. URL : http://journals.openedition.org/studifrancesi/44759 ; DOI : https://doi.org/ 10.4000/studifrancesi.44759

Ce document a été généré automatiquement le 15 octobre 2022.

\section{(†) $\odot$

Creative Commons - Attribution - Pas d'Utilisation Commerciale - Pas de Modification 4.0 International - CC BY-NC-ND 4.0

https://creativecommons.org/licenses/by-nc-nd/4.0/ 


\title{
Les Quinze joies de mariage, édité par J. RYCHNEr, traduit par J.-C. MÜHLETHALER
}

\author{
Maria Colombo Timelli
}

\section{RÉFÉRENCE}

Les Quinze joies de mariage, édité par J. RYCHNER, traduit par J.-C. MÜHLETHALER, Genève, Droz, 2020, «Texte courant» 13, 358 pp.

Dans une collection qui a pour but de diffuser des textes médiévaux qui méritent d'être connus par un public large, Les Quinze joies de mariage trouvent toute leur place. L'édition fournie par Jean Rychner en 1967 demeurant irremplaçable, elle est reproduite ici dans toutes ses parties: Introduction, texte critique, glossaire et index; mais qu'on soit rassuré: l'Invitation à la lecture fournie par Jean-Claude Mühlethaler, ainsi que sa traduction en français moderne, rendent à ce recueil toute leur fraîcheur en en soulignant la modernité. Le sous-titre sous forme d'interrogation «Pourquoi et comment lire les Quinze joie de mariage aujourd'hui?» (p. LXvII) couvre à la fois une mise en garde contre «les dangers que comporte la projection d'une sensibilité moderne sur un texte ancien» (p. xcII) et une invitation à «chercher dans les Quinze joies ce qui entre en résonance avec nos intérêts et nos interrogations d'aujourd'hui» (p. LXXVII). Dans des pages denses d'information mais d'une lecture très agréable J.-Cl.M. accompagne ainsi le lecteur vers ce texte produit, rappelons-le, vers 1400, en profitant au mieux de la bibliographie parue après l'édition Rychner, dont il aura retenu les apports essentiels.

Les quinze morceaux qui composent le recueil médiéval proposent une double satire, de la femme et du mariage, qui garde toute sa valeur, si tant est que nous arrivons à nous libérer du «politically correct» pour jouir du plaisir de ces pages, où l'auteur anonyme jongle entre les topoï mysogines les plus exploités, les portraits de types et les tableaux de situations, la généralisation se faisant grâce à l'emploi savant de quelques 
procédés linguistiques que la critique a reconnus depuis longtemps: propositions alternatives, futur de narration, récurrence de la locution par aventure. Quelques «pistes pour une lecture actualisante» sont offertes (pp. LXxxvi et ss.), où J.-Cl.M. montre bien que l'auteur anonyme tend aux lecteurs que nous sommes «un miroir, dans lequel se reflètent (aussi) les hantises de notre temps» (p. xc); «œuvre ouverte», donc, qui ne saurait laisser indifférent le public d'aujourd'hui, qui retrouvera avec plaisir des scènes de son quotidien et sans doute aussi son propre portrait - en surmontant d'un seul bond la distance chronologique avec un recueil paru il y a quelque six siècles. Le lecteur mieux informé, lui, redécouvrira volontiers une édition critique offerte par un maître des études médiévales accompagnée d'une traduction capable de rendre au texte toute sa verve, sa vivacité, sa modernité. 